\title{
Changing Patterns in Process Management and Improvement: Using RPA and RDA in Non- Manufacturing Organizations
}

\author{
Gedas Baranauskas \\ Mykolas Romeris University, Lithuania
}

Doi:10.19044/esj.2018.v14n26p251 URL:http://dx.doi.org/10.19044/esj.2018.v14n26p251

\begin{abstract}
Being, from the first sight, a complementary part of process management within an organization, process management automation draws a very broad and promising perspective to the whole business field since it is a step closer to the smarter and next level efficiency. Therefore, this particular theoretical scientific research elaborates the topic of the application of Robotic Process Automation (RPA) and Robotic Desktop Automation (RDA) concepts within the work activities in non-manufacturing organizations as this is a non-widely examined area and offers the whole specter of opportunities. Therefore, focuses are based on process management in organizations where client service is key activity and direction with soft systems and operations used as working tools. In addition, a comparative analysis of key similarities and differences of terms and practical application of RPA/RDA within the manufacturing and non-manufacturing sector is provided. Problematic areas, which this particular topic escalates, have a wide framework: first, it is noticed that the scientific field regarding the application of RPA and related concepts in combination with other process management methods (for example, Lean, Agile or Business Process Management (BPM)) has not been widely discussed. Second, in generally most of the past and ongoing scientific researches and practices tendencies and problems in process automation within the manufacturing sector field have been investigated. Accordingly, it is missing both quantitative and qualitative analyses of past and current situations in non-manufacturing business and public organizations. To generalize, it is agreed that process automation has made a notorious impact not only on the tendencies of process management within the business field but also on a society as a human resource. Therefore, investigation of this topic as a very relevant subject is essential since it has a direct and very strong impact on business cycles, technological evolution, and job market.
\end{abstract}


Keywords: Process automation, robotic, RPA, RDA, robot, manufacturing and non-manufacturing organizations

\section{Introduction:}

In recent three decades the content and direction of business process management as well as synergy and combinations with other management concepts or ideas have been widely discussed and applied both in the scientific research field and in the working environment (Singh \& Singh, 2013; Huxley, 2015; Qamar et al., 2018; Danese \& Manfè, 2017; Raišienè, 2015). Outstanding qualitative changes of information technology and the Internet platform in last decade of XX century affected and encouraged organizations focusing on optimization of operations and systems (Kehoe et al., 2015). Starting with the initial phase of Business Process Reengineering (BPR) and moving later to Business Process Management (BPM), Lean and Hybrid (integrated) methods modern organizations now are leveraging the efficiency of Robotic Process Automation (RPA) and Robotic Desktop Automation (Danese \& Manfè, 2017; Bhaskar, 2018). It is agreed that organizations which have switched to these methods are able not only to improve and optimize the indicators of operations and resource utilization, but boost financial transparency, modernize and standardize workflow, minimize errors and create better conditions for becoming a so called customer-people oriented organization. Otherwise, most of the researches are oriented to topics of process automation and human and machine interaction in manufacturing without consideration and comparison to the service type of organizations in private or public sectors (Bolle et al, 2015; The Institute for Robotics Process Automation, 2015; Kolberg \& Zühlke, 2015). It worth to mention that public sector enterprises lacks RPA or RDA technologies in their general activities as, in most cases, they see these tools not as the main solution regarding rising their revenue. Instead, they set up RPA/RDA solutions for ensuring better level of service customization by paying more attention to specific customized details, consumers habits or needs, trends in society and providing in accordance a high quality of services and relevant information to citizens by following 24/7 service and Single Entry standards (Kasim et al., 2018; Gabryelczyk \& Jurczuk, 2016). Therefore, as follows, the comparative theoretical background based analysis is conducted and key points and differences in semantical meaning and practical implementation within different types of organizations are revealed.

\section{The key features and semantical meaning of process automation in modern organizations}

Origins of terms Process Automation and Robotics are linked to the first half and middle of the XX century; ideas and practices belonging to the 
F. W. Tailor's scientific management concept and the H. Ford's management theory (Ostdisck, 2016, Lhuer, 2016). Focus to process coordination, better machine and human resource allocation and strict workflow guidelines lead to Lean concept and now are used as a framework in combined process automation related activities too (Singh \& Singh, 2013). On the other hand, historically, process optimization was primary adopted in automotive manufacturing and industrial field and in relation to the understanding of mentioned terms were formulated, which later affected content of terms Robot, Robotic Process Automation or Robotic Desktop Automation too (Yusupbekov et al., 2017; Royakkers\&Est, 2015). But in modern, service based and customer oriented organization, currently it serves in a different way and context, so the main features of these terms should be described in accordance.

From the perspective of practical implementation, Robotic Process Automation (RPA) is considered as a software applied in fully and independently working automation for a part of work activities or overall process, which typically are done by human resources (Lacity\&Willcocks, 2016). In this context, RPA and its application has also a wider semantical meaning. It carries a meaning of a better quality of service or product, process agility and changes in lead time, or Service Level Agreement (SLA), for the customer. It means not only new functionalities and features to operation object, but also changing needs and interaction points of human worker as well as creating a new brand for the organization (PEGA, 2016).

Taking into evaluation the position of The Institute for Robotics Process Automation, it should be mentioned that RPA is considered as technology based on smart software and its usage for the large scope, both in time and quantity indicators, repeating type of daily tasks, which typically are done by human (The Institute for Robotics Process Automation, 2015). Practice from „Deloitte Insights“ showing similar understanding and RPA is characterized as a software for automation activities of processes which has strict rules and work guidelines, limited numbers of deviations or possibility of ad hoc situations (Iyengar et al., 2016). In summary, it can be stated that RPA in modern, service oriented organizations has these main features:

Table no. 1. The main features of RPA concept

\begin{tabular}{|c|c|c|}
\hline Semantical meaning & Key content features & $\begin{array}{c}\text { Aims of practical } \\
\text { application }\end{array}$ \\
\hline Software application & Mathematical algorithm & $\begin{array}{c}\text { Reduce of routine, } \\
\text { repeating and large scope } \\
\text { of tasks }\end{array}$ \\
\hline New working method & $\begin{array}{c}\text { Standardized process and } \\
\text { limited options of selection }\end{array}$ & $\begin{array}{c}\text { Increased level of } \\
\text { customer satisfaction }\end{array}$ \\
\hline
\end{tabular}




\begin{tabular}{|c|c|c|}
\hline $\begin{array}{c}\text { Assisting tool for managers } \\
\text { and workers }\end{array}$ & No decision making & $\begin{array}{c}\text { Overall better quantitative } \\
\text { and qualitative indicators }\end{array}$ \\
\hline $\begin{array}{c}\text { Overall process } \\
\text { optimization and } \\
\text { improvement }\end{array}$ & $\begin{array}{c}\text { Limited or non-human } \\
\text { resource interaction }\end{array}$ & - \\
\hline
\end{tabular}

Source: made by author following The Institute for Robotics Process Automation, 2015; Iyengar et al., 2016; Lacity\&Willcocks, 2016; PEGA, 2016.

So RPA can be summarized as an IT based imitation of human daily work where a limited number of autonomous decisions are needed and, in most cases, great numbers in quantity should be done in a short period of time. Looking at the table above it also can be identified that RPA content is similar and related to other methods or concepts used in process management improvement called: Business Process Reengineering (BPR) and Business Process Management (BPM) as models of workflow management, a customer orientation based SIPOC model or Lean (Kadarova\&Demecko, 2016; Kolberg\&Zühlke, 2015; Kawa\&Maryniak, 2018). In other words, it could be described as a continuous process improvement, post or next stage of mentioned methods application in modern organization. It is important to state that Robotic Desktop Automation (RDA) is widespread in practical approach and is often closely related to RPA based solutions. RDA is a technology software performing locally, which is repeating human worker steps by an interaction with other interactive systems and operator. Key feature is that this technology software is depended and acting only when given a permission-activation by an operator (Kehoe et al., 2015, The Institute for Robotics Process Automation, 2015). In compare to RPA, there are a few key features that differ these two tools. The table below defines at which points RPA and RDA solutions have same or different characteristics:

Table no. 2. The main matches and mismatches between concepts of RPA and RDA

\begin{tabular}{|c|c|}
\hline Category of evaluation & Concept of RPA and RDA \\
\hline Semantical meaning & Match \\
\hline Aims of application & Match \\
\hline Effect for process & Match \\
\hline Principles of working & Partly match \\
\hline Level of organizational maturity & Partly match \\
\hline Need of resources & Not match \\
\hline Role of human worker & Not match \\
\hline
\end{tabular}

Source: made by author following Kehoe et al., 2015, The Institute for Robotics Process Automation, 2015; Iyengar et al., 2016; Lacity\&Willcocks, 2016

So, as can be seen from the table above, only in 3 of 7 total categories concepts of RPA and RDA are described as similar and matching: semantical meaning, aims of application and effect for selected processes. At this point, it should be mentioned that these matches are more related to a wider context of evaluation and has a strong relation to overall content of robotic automation 
term (Ostdisck, 2016, Yusupbekov et al., 2017; Anagnoste, 2017). Both of compared terms include a modern technology software which is used in daily work to reduce non-value creating steps, create more customization as well as improving resource usage and allocation. In this comparative analysis there are also a few categories which can be called as intermediate. It was formulated due to the fact that a few parts of categories are recognized in both type of process automation: principles of working and level of organizational maturity. Principles of working describe clear rules and steps in process used in Robotic Process Automation and Robotic Desktop Automation: standardization and documentation of process, using database and other IT type resources in organization, interaction with human worker-operator (Ogbemh et al., 2017, International Standardization Organization, 2012) . Relating the maturity level, both measuring status of process management and evaluating capabilities of automation in specific enterprise are included. From the perspective of the maturity in process management, the main measurement models are adapted: the Capability Maturity Model (CMM) created by Software Engineering Institute (SEI), later developed to the Capability Maturity Model Integration (CMMI); the model from Bill Curtis and John Alden Business Process Maturity Model (BPMM); The Process and Enterprise Maturity Model (PEMM) from Hammer \& Co or Seven Tenets from APQC organization (Heller\&Varney, 2013; Torrecilla-Salinas, 2016). In parallel, the practice shows that organizations apply the Automation Maturity Model too. It allows measuring an ongoing level of organizations' maturity in automation and planning initiatives that are required to achieve the next level of processes automation and productivity gains (Kumar, 2016). Taking into consideration the main mismatches of these two technologies software, a need of resources and the role of human worker-operator are influential. When using RDA automation, complex, integral and different type and number of processes can be performed easily: a human workeroperator controls the process flow from the start to the end step; stops the process if needed as well as overtakes the rest human decision making based part of process from the robot, acting in a typical working schedule. From this point, RDA is seen as better and more commonly used solution in manufacturing organizations than RPA (Bolle, 2015; Yusupbekov et al., 2017) .

Taking into consideration manufacturing, the dominance of the term Robot can be identified at this point. A Robot is considered as a physical machine which replaces handcrafting actions or all processes in different type of manufactories (Ogbemhe, 2016; Pedersen et al., 2016). According to the standard of International Standardization Organization (ISO), a robot is a device set up to perform an independent action in strict rules based 
environment (International Standardization Organization, 2012). There are two main types of robots in manufacturing:

- With integrated, independent control system and non-integrated control system, managed by human worker from the distance and/or integrated human-automation-systems (HAS);

- Oriented and specified for using in manufacturing and oriented and specified for using in client service type of organizations (Cherubini et al., 2016; .

Accordingly, the process of Robotic Process Automation in this sector is also related and best characterized by creating a psychical entity, a robot, and seeking for improvement of process reliability and quality. In this context, human worker-operator due to his working experience, knowledge and expertise still plays a central role whereas the automation solution performs physical operation with guidance and supervision with human (Pedersen et al., 2016; Langer\& Söffker, 2015) . While in a client service oriented or financial type of organizations as mentioned this is mainly understood as IT technology and software solutions acting autonomously or with a minimal human interaction for any type and part of process. It is used both separately or in combination with other methods for overall process improvement and as a new standard of process management. On the other hand, in both sectors similar issues affect these terms: how to ensure the right proportion and point of human interaction, how to manage certain challenges especially in the complexity of the resulting automation solution or ensure alignment with other processes, systems and preferences of human workers (Langer\& Söffker, 2015; Yusupbekov et al., 2017, Raišienè, 2011; The Institute for Robotics Process Automation, 2015; Tomov, 2017).

\section{Tendencies, issues and possibilities of robotic solutions for process improvement in non-manufacturing organizations}

Tendencies, issues and possibilities of robotic solutions in nonmanufacturing organizations are not isolated and influenced by overall tendencies and innovations in robotic field. Last tendencies in manufacturing show a direction of improving technical and cognitive side of robots and leads to widespread of self-reconfiguring robotic systems or self-reconfigurable modular robots. At the same time, their weight is reduced, agility and balance increase as well as interaction with other mobile devices or applications elaborated (International Federation of Robotics, 2016; Yusupbekov et al., 2017). Recent practices in this sector are based on increasing numbers of integrated human-automation-systems (HAS) and its application in wide range of spheres too. For example, in tactical operation design, producing unmanned vehicles or flight service automation. It is worth to mention that the last automation solutions are used not only for improvement of qualitative or 
quantitative indicators but also to support the human operator's situation awareness (SA) in complexity gaining environments (Langer\& Söffker, 2015; Pedersen et al., 2016). Following Langer and colleagues position if a role of robot and robotic application in handcrafting actions based organizations is cleared and coordinated as well as described by the human-machine-interface (HMI) term, in non-manufacturing organizations it is oriented to the machineprocess-interface (MPI). All the process flow and key points can be illustrated by the scheme below:

Illustration no. 1. The content and process flow of Automation

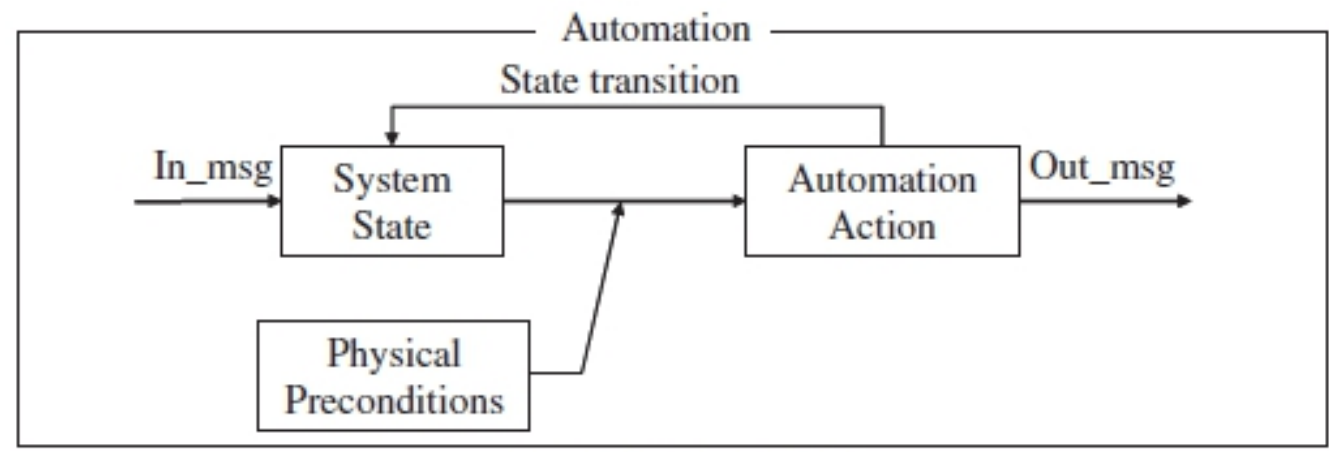

(a) Automation model

Source: Rothrock et al., 2006

In this standard automation process model, three main parts play a role: human worker, automation solutions and environment-interface. A typical process flow starts with an input message named In-msg within which a process is determined by a certain [not automated] state System state. This process is affected by specific external or internal physical preconditions with limited control options. At this point automation solutions/actions can be used to stabilize the process or workflow and create a desired process output Out_msg. In addition, this process flow is cyclic and might be continuously improved in an automated way (Rothrock et al., 2006).

In parallel, future development tendencies should be described: it is recognized that in modern business environment and conditions organizations deal with high complexity, dynamic and integral processes or systems. In accordance, the automated solutions should be oriented not only to ComputerIntegrated Manufacturing (CIM) and Control processes and systems, but also to Supply Chain Management (SCM), Customer Relationship Management (CRM), Data security via Cloud computing technology (Damasceno et al., 2015; Jha\&Mohapatra, 2017; Tomov, 2017; Anagnoste, 2017). From the perspective of governmental or non-governmental organizations, tendencies of robotic application have a direction and aim not only towards an increasing process and resource management effectiveness but more attention to 
processes customization is paid, while prioritizing high quality, fast, 24/7 ideology focused on services and provision of relevant information to citizens and third parties (Kasim et al., 2018; Gabryelczyk \& Jurczuk, 2016). In addition, concrete changes and transformations in process management are possible:

- Creating more transparent and open mindset in internal and external processes across the organization;

- Modernizing back and front-end administrative processes;

- Improving tracking, processing and reporting of processes for audit or regulatory purposes;

- Improving decision making process (Jha\&Mohapatra, 2017).

At this point, the greatest challenge in public sector refers to not gaining impressive numbers of productivity increase or discovering new product or service solutions which would fit to a large scale of end users (Gabryelczyk \& Jurczuk, 2016). Finding methods or their combination for creating rational and well-designed processes, increasing accountability and participation rates are biggest targets in this context. Thus, the main goal of adapting ideas of hybrid (integrated) methods and mass customization concept in public enterprises can be described as sustainable, cost-effective and transparent performance (Rodgers et al., 2018; Raišienè, 2016).

Talking about possibilities of robotic automation application in nonmanufacturing organization, a few key points should be mentioned:

a) Evaluation of task complexity. Firstly, the measurement with prioritization of tasks, or candidates for robotic, is made. To be more specific, it depends on the level of difficulty - all the processes or tasks at this point might be divided into segments by an average number of requests per week, varying from low (less than 150 requests per week) to high (more 1000 per week) number. In addition, the indicators of implementation time in parallel to task complexity are measured and three main groups are outlined:

1) Simple (low) complexity tasks with a short period of handling (up to 4 minutes);

2) Medium complexity tasks with a medium period of handling (from 4 to 30 minutes);

3) Complex tasks with a long period of handling (more than 30 minutes) (Lacity\&Willcocks, 2016).

Overall, consideration of these two main parameters can be visualized in dynamic matrix below: 
Illustration no 2. Dependency between indicators of workload and task complexity in automation

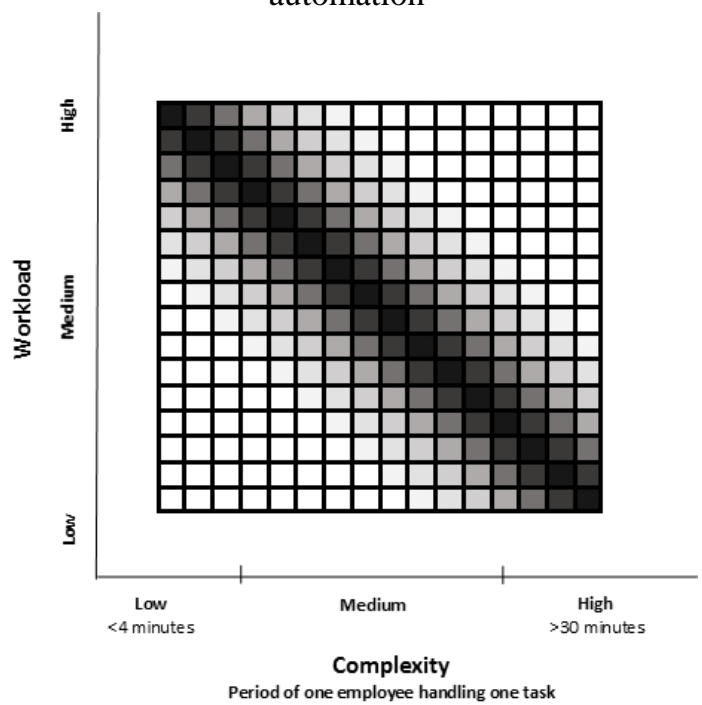

Source: made by author following Lacity\&Willcocks, 2016

b) Forecasting possible financial and time savings are considered. Here, the indicators of Return of Investment (ROI) and Full Time Employee (FTE) are important. Research show that level of ROI after the first year of automation varies from 30\% to 200\% (Lacity\&Willcocks, 2016; Lhuer, 2016; Iyengar et al., 2016). Possible reduction of human resource number in process has a dual meaning in this context: it allows relocating financial resources to new investment or salary increases for the rest part of staff. However, on the other hand it requires having a prepared action plan for the best knowledge share and saving after experienced employee leaving as well as controlling ad hoc situations in process and resistance from employee, ensuring employee retraining and positive microclimate during the transformation period. At this point, before and after the implementation of robotic process automation at public sector some issues arise: it is noticed that mentioned resistance to this type of changes are related to the structure of the workforce in this sector, poor risk and general process management skills and complex process content. The first one is related both to tendencies of workforce and its features in this sector as well as worries that constant or decreased numbers of servants as well as their time resource limitations do not let coping with daily tasks and backlogs, fast changing environment, big amount of data and requirements of process improvement (Hilgers\&Piller, 2011; Mergel, 2016; Shanab, 2015).

c) Evaluation of organizational and processes maturity level. At this point, for example using a Capability Maturity Model Integration (CMMI) version 1.3 as process management and behavioral model can provide insights for baselining and optimizing organizational capabilities, streamlining and 
encouraging process improvement, reducing risks in product or service development through robotics.

Finally, the best practices and ideas from traditional Level of Automation (LoA) model, introduced by Endsley (1987) and extended later by several authors, are used in automation related processes. At this point, analyses regarding automation in non-manufacturing organizations combining above mentioned key points and overall deducing research from a top-level and a two-dimensional view along information analyses and action implementation (Langer\& Söffker, 2015). In compare with manufacturing, some additional indicators are measured in context of industrial robot creation: increase of delivery time and product features in quality; agility of application; alignment with human worker and other organizational systems (Royakkers\&Est, 2015).

\section{Conclusion:}

Origins of scientific terms in context of process automation and first practical application are linked to the first half and the middle of the $\mathrm{XX}$ century and automotive industry. Therefore, development tendencies and main issues in robotic solutions in non-manufacturing organizations are not isolated and are influenced by overall tendencies and innovations in robotic field, especially manufacturing.

Otherwise in modern non manufacturing type of organizations, where dominant of processes and systems are oriented to customer service, terms of robotic and process automation have different features and semantical meaning. Most common used terms are a Robotic Process Automation (RPA) and Robotic Desktop Automation (RDA). Both are considered as a technology-software applied for a different scale of autonomous of automation in daily work activities or overall process, which typically are done by human resources. It is worth to mention that the last automation solutions are oriented not only to improvement of qualitative or quantitative indicators but also to increase the human operator's situation awareness (SA) in complexity gaining environments.

Talking about possibilities of robotic automation application in nonmanufacturing organizations, a few key points should be evaluated: profile of a task (complexity); possible financial and time savings, organizational and processes maturity level. In addition, the overall deducing research from a toplevel and a two-dimensional view along with an information analysis and action implementation are made.

It should be mentioned that some parts of RPA content are similar and related to other methods or concepts used in process management or continuously process improvement: Business Process Reengineering (BPR) and Business Process Management (BPM), SIPOC model or Lean concept. 
Taking manufacturing into comparison, the dominance of the term Robot as physical machine can be identified. So the processes of Robotic Process Automation in this sector are also related and best characterized by creating a psychical entity, a robot, and seeking in priority for an improvement of process reliability and quality. On the other hand, in both sectors both terms RPA and RDA are affected by similar issues: ensuring the right proportion and point of human interaction; managing challenges and deviation after implication of automation solutions; ensuring alignment with other processes, systems and preferences of human workers. From the perspective of future development, it is recognized that mentioned automation solutions will help organizations to keep or gain a competitive advantage and deal with high complexity, dynamic and integral processes or systems. In accordance, the automated solutions are becoming oriented not only to Computer-Integrated Manufacturing (CIM)) and Control processes and systems, but also to a wider scope: for example to Supply Chain Management (SCM), Customer Relationship Management (CRM), Data security via Cloud computing technology. Therefore, RPA and RDA can be identified as a direct way towards a faster, more agile and better customer service presenting business where good customer experience and high levels of efficiency are key orientation.

\section{References:}

1. Anagnoste, S. (2017). Robotic Automation Process - The next major revolution in terms of back office operations improvement. Conference: Proceedings of the 11th International Conference on Business Excellence, 676-686.

2. Bhaskar, H. L. (2018). Business process reengineering: A process based management tool. Serbian Journal of Management, 13(1), 6387.

3. Bolle, M., Lorenz, M., Lueth, K. L., Russmann, M., Strack, R. (2015). Man and Machine Industry 4.0. The Boston Consulting Group. Link via Internet: (http://englishbulletin.adapt.it/wpcontent/uploads/2015/10/BCG_Man_and_Machine_in_Industry_4_0 _Sep_2015_tcm80-197250.pdf).

4. Cherubini, A., Passama, R., Crosnier, A., Lasnier, A., Fraiss, P. Collaborative manufacturing with physical human-robot interaction. Robotics and Computer-Integrated Manufacturing, 40, 1-13.

5. Damasceno, J., Lins, F., Medeiros, R., Rosa, N., Sousa, E. (2015). Automation of service-based security-aware business processes in the Cloud. Computing, 98(9), 847-855.

6. Danese, P., Manfè, V. (2017). A Systematic Literature Review on Recent Lean Research: State-of-the-art and Future Directions. International Journal of Management Reviews 20(2), 579-582. 
7. Gabryelczyk, R, Jurczuk, A. (2016). Business process management in the public sector: explored and future research fields. Conference: 9 th Annual Conference of the EuroMed Academy of Business: Innovation, Entrepreneurship and Digital Ecosystems, EuroMed Press, 786-799.

8. Heller, A., Varney, J. (2013). Using Process Management Maturity Models: a path to attaining process management excellence. APQC. Link via

Internet: http://portailqualite.acodev.be/fr/system/files/node/284/using_process _management_maturity_models.pdf

9. Hilgers, D., Piller, F. T. (2011). A Government 2.0: Fostering Public Sector Rethinking by Open Innovation. Innovation Management, 1-8.

10. Huxley, C. (2015). Three Decades of Lean Production: Practice, Ideology, and Resistance. International Journal of Sociology, 45,137139.

11. ISO. (2012). ISO 8373:2012(en): Robots and robotic devices Vocabulary Link via Internet: (https://www.iso.org/obp/ui/\#iso:std:iso:8373:ed-2:v1:en).

12. Iyengar, K., Muraskin, C., Schatsky, D. (2016). Robotic process automation. Deloitte Insights [interaktyvus]. Link via internet: https://www2.deloitte.com/insights/us/en/focus/signals-forstrategists/cognitive-enterprise-robotic-process-automation.html)

13. Jha, S., Mohapatra, A.K. (2017). Process Automation for Operational Excellence at HelpAge India. Review of Management, 7(3-4), 5-8.

14. Kadarova, J., Demecko, M. (2016). New approaches in Lean Management. Procedia Economics and Finance, 39, 11-16.

15. Kasim T., Haračić M. ,Haračić M. (2018). The improvement of business efficiency through business process management. Economic Review: Journal of Economics and Business, 16(1), 31-43.

16. Kawa, A., Maryniak, A. (2018). Lean and Agile Supply Chains of Ecommerce in Terms of Customer Value Creation. Modern Approaches for Intelligent Information and Database Systems, 317-319.

17. Kehoe, B., Patil, S., Abbeel, P., Goldberg, K. (2015). A Survey of Research on Cloud Robotics and Automation. IEEE transactions on automation science and engineering, 12(2), 398-405.

18. Kolberg, D., Zühlke, D. (2015). Lean Automation enabled by Industry 4.0 Technologies. IFAC-PapersOnLine , 48(3), 1870-1875.

19. Kumar, R. (2016). Measure your Enterprise Automation with Mindtree's Automation Maturity Model. Mindtree. Link via Internet: https://www.mindtree.com/blog/measure-your-enterprise-automationmindtrees-automation-maturity-model

20. Lacity, M.C., Willcocks, L. P. (2016). Robotic Process Automation at Telefónica O2. MIS Quarterly Executive, 15(1), 21-36. 
21. Langer, M., Söffker, D. (2015). Event-discrete formal representation of a semi-automated manufacturing process as framework for human guidance and assistance concepts: analysis and application. International Journal of Production Research, 53(8), 2321-2341.

22. Lhuer, X. (2016). The next acronym you need to know about: RPA (robotic process automation). McKinsey \& Company Link via Internet: (https://www.mckinsey.com/business-functions/digitalmckinsey/our-insights/the-next-acronym-you-need-to-know-aboutrpa).

23. Mergel, I. (2016). Agile innovation management in government: A research agenda. Government Information Quarterly, 33 (3), 516-523.

24. Ogbemhe, J., Mpofu, K., Tlale, N. S. (2017). Achieving Sustainability in Manufacturing Using Robotic Methodologies. Procedia Manufacturing, 8, 440-446.

25. Ostdisck, N. (2016). The Evolution of RPA: Past, Present, and Future. UiPath Link via Internet: https://www.uipath.com/blog/the-evolutionof-rpa-past-present-and-future).

26. Pedersen, M. R., Nalpantidis, L., Andersen, R. S., Schou, C., Bøgh, S., Krüger, V., Madsen, O. (2016). Robot skills for manufacturing: From concept to industrial deployment. Robotics and Computer-Integrated Manufacturing, 37, 282-291.

27. Qamar, A., Hall, M. A, Collinson, S. (2018). Lean versus agile production: flexibility trade-offs within the automotive supply chain. International Journal of Production Research, 56, 3974-3993.

28. Raišienè A.G. (2011). Advantages and limitations of integrated management system: The theoretical viewpoint. Social Technologies, 1(1), p. 25-36.

29. Raišienè A.G. (2016). Performance success factors in hybrid organizations. In: Innovation, Entrepreneurship and Digital Ecosystems (Vrontis D., Weber Y., Tsoukatos E., Eds.) p. 1531-1538, EuroMed Press.

30. Raišienè, A.G. (2015). Business and management success: what course is supported by sustainable organization managers? Transformation in Business \& Economics, 14(3), 68-91.

31. Robotic Process Automation. (2016). PEGA. Link via Internet: (https://www.pega.com/rpa).

32. Rodgers, B. A., Antony, J., Kregel, I. (2018). The role of government in leadership for Lean Six Sigma in the public sector. Conference: Conference: 7th International Conference on Lean Six Sigma, At Dubai, United Arab Emirates.

33. Rothrock, Ling; Shin, D.; Wysk, R. (2006). A. A formal controltheoretic model of a human-automation interactive manufacturing 
system control. International Journal of Production Research. 44(20), 4273-4295.

34. Royakkers, L., Est van R. (2015). A Literature Review on New Robotics: Automation from Love to War. International Journal of Social Robotics, 7(5), 549-570.

35. Shanab, E. A. A. (2015). Reengineering the open government concept: An empirical support for a proposed model. Government Information Quarterly, 32 (4), 453-463.

36. Singh, J., Singh, H. (2013). Continuous Improvement Strategies: An Overview. Journal of Operations Management, 13(1), 33.

37. The Institute for Robotics Process Automation (2015). Introduction to Robotic Process Automation: A Primer . 2015 Link via Internet: (https://irpaai.com//wp-content/uploads/2015/05/Robotic-ProcessAutomation-June2015.pdf).

38. Tomov, P. (2017). Increasing the Efficiency of Automation of Production Processes by Reporting the Parameters of the Parts ' Flow. TEM Journal, 6(3), 484-487.

39. Torrecilla-Salinas, C., Sedeño, J., Escalona, M., Mejías, M. (2016). Agile, Web Engineering and Capability Maturity Model Integration: A systematic literature review. Inf. Softw. Technol., 71, 92-107.

40. Yusupbekov, N, Adilov, F., Ergashev, F. (2017). Development and improvement of automation and management of technological processes and manufactures. Journal of Automation, Mobile Robotics \& Intelligent Systems, 11(3), 53-57. 